$16^{\text {th }}$ International Conference on

AEROSPACE SCIENCES \& AVIATION TECHNOLOGY,

ASAT - 16 - May 26 - 28, 2015, E-Mail: asat@mtc.edu.eg Military Technical College, Kobry Elkobbah, Cairo, Egypt

Tel : +(202) 24025292 - 24036138, Fax: +(202) 22621908

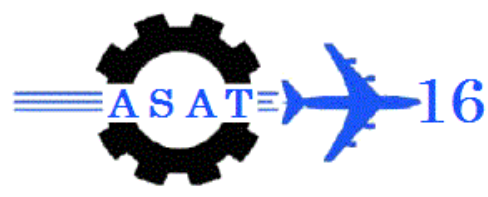

\title{
Plate Thickness Effect on the Fracture Pattern Morphology of Fatigue Loaded Friction Stir Welded DH-36 Steel \\ M. Osman
}

\begin{abstract}
:
As a part of evaluating the Friction Stir Welding (FSW) performance of DH-36 steel, the fracture surfaces of the friction stir welded tensile specimens were observed after fracture under both a monotonic axial and a cyclic loading. Monotonically loaded welded specimens always fracture on the parent material in a typical ductile behavior. Fatigue loading creates stress concentrators in the material surface by the stir tool shoulder. Surface micro-cracks are nucleated in the vicinity of the stress concentrators and propagate in different patterns depending on the plate thickness causing the material failure. In this paper, microstructure of the weld region, microhardness variation and state of stress on the nucleated cracks tip are studied and correlated to the observed fracture patterns.
\end{abstract}

Key words:

Friction stir welded steel, DH-36, Crack tip stress intensity.

* Egyptian Armed Forces 


\section{Introduction:}

The continually increasing demands of the heavy manufacturing industries on these welding techniques, performing lower axial/transverse distortions and low residual stresses such as FSW, motivates many researchers to investigate the resulting weld and characterize thoroughly its performance. Aluminum alloys received most of this attention since this technique was invented by the Technical Welding Institute (TWI) in 1991 [1,2]. Mishra and Ma [ 3 ] reviewed the friction stir welding and friction stir processing in different aluminum, copper, magnesium and steel alloys. In aluminum alloys, the mechanical properties of the stirred zone considerably change as a function of the constitution of the alloy which determines the nature of the possible strengthening mechanisms. In case of the precipitation age hardened aluminum alloys, material softening around the weld center is observed. The measured reduction in hardness was explained in terms of either coarsening or dissolution of the dispersed precipitates, during the FSW thermal cycle, especially those on the grain boundaries [4-7]. Solid solution strengthened aluminum alloys showed no softening effect whereas there are no precipitates to be dissolved or to lose their coherency [8-9]. Pure aluminum showed also an improved hardening effect due to the grains refinement that always takes place during the process of stirring [8]. Different categories of steel alloys, having a wide range of both chemical and mechanical characteristics were studied extensively. The microstructures of the friction stir welded (FSWd) zones as well as their mechanical behavior were investigated in the case of low carbon and chromium steels [10], mild steels [11-12], austenitic stainless steels [13-16], HSLA-65 steel [17], DH-36 steel [18-19] and finally the C-Mn steels [20]. All these alloys showed a hardening performance in the weld zone except the C-Mn steel category which showed a drop of the mechanical characteristics attributed to the newly formed phases. On the other hand, austenitic low carbon stainless steel (304L) was reported to have the highest overmatching where its weld yield strength and hardness were almost double those values of the parent material due to the extensive strain hardening effect [18]. This hardening effect was found to improve the fatigue behavior of the FSWd joint, where it resists the crack nucleation under fatigue loading compared with the parent material. The harder weld zone suppresses the crack nucleation in the sharp root of the tool shoulder marks and delays its initiation. Cracks tip having different stress intensity factor $K$ interact unlikely with the present phases having discreet hardness ranges that controls its propagation. Tool marks on the top surface of the FSWd joint were found to act as stress concentrators and consequently as a source of micro-cracks initiation. Effect of these pre-existing stress risers has been studied extensively in both the longitudinal and traverse directions of the weld [21-22]. Skimming the tool shoulder marks from the welded surface increases the measured fatigue strength to more than double the original value. However, the objective of this work is to evaluate the microstructure variation along the different weld zones, hardness profile of the stirred zone and to study 
the effect of the weld thickness on the stress intensity factor. Furthermore, to establish the interrelation between these variations and the corresponding fracture pattern.

\section{Experimental work:}

Rolled DH-36 steel plates were supplied with different thicknesses 4, 6 and 8 $\mathrm{mm}$ respectively, having $2000 \mathrm{~mm}$ in length along the rolling direction and 300 $\mathrm{mm}$ in width. Constitution of this alloy contains $0.14 \% \mathrm{C}, 1.34 \% \mathrm{Mn}$ and $0.37 \% \mathrm{Si}$ as major alloying elements, whereas $\mathrm{Nb}$ as minors. All the supplied plates were checked for their chemical composition that showed a carbon equivalent of $0.37 \%$. The plates were FSWd along their rolling direction using the TWI's Power Stir computer controlled friction stir welding machine. All the welds were carried out under the same axial force of $60 \mathrm{KN}$ in the vertical $\mathrm{Z}$ axis, a rotation speed of $250 \mathrm{rev} / \mathrm{min}$ in the counter clock wise CCW and a welding traverse speed of $125 \mathrm{~mm} / \mathrm{min}$. Constant welding conditions were decided to eliminate the effect of the welding parameters and to compare the fracture patterns in basis of plate thickness only. MegaStir tools with polycrystalline boron nitride ( $\mathrm{PCBN}$ ) Q70 pins were used to weld the plates with pin length of 4,6 and $8 \mathrm{~mm}$ respectively. Tensile specimens according to the British Standard (BS EN ISO 148-1:2010) were cut perpendicular to the weld line as shown in Fig (1).

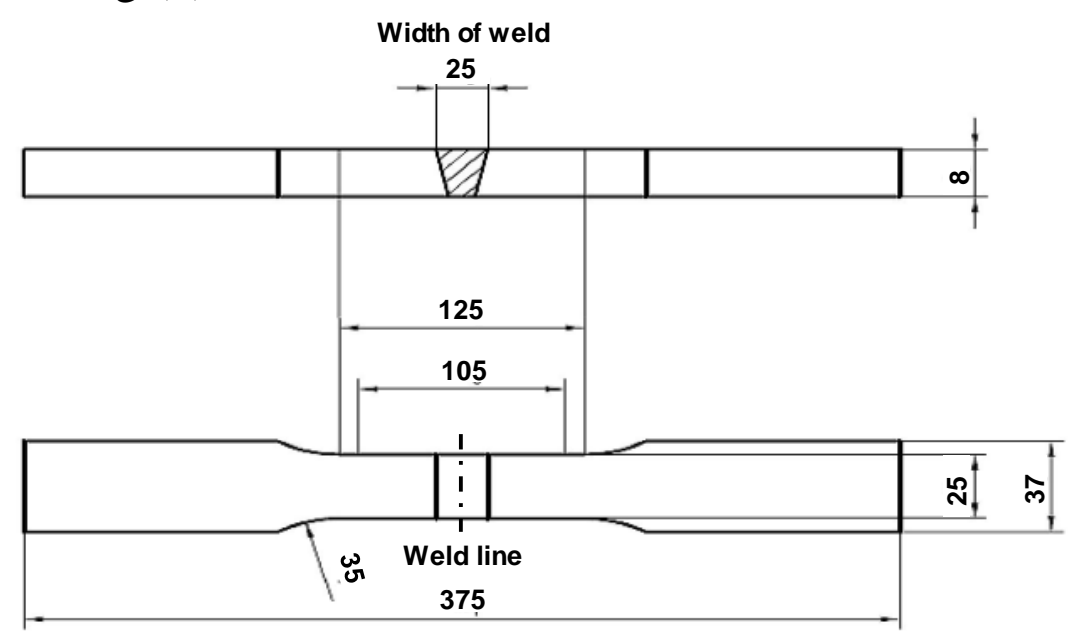

Fig. 1. Orientation of the tensile specimen with respect to the weld

The microstructure of the as received material as well as that for the weld were optically investigated in the transverse plane (perpendicular to the weld line) using an Olympus GX-51 metallurgical microscope. The fracture surfaces were investigated with a HITACHI large chamber scanning electron microscope model S-3700. Fatigue loading was performed in the Advanced Material Research Lab (AMRL) in Strathclyde University using the servo-hydraulic 8800 series Instron machines. A fatigue test with sinusoidal loading cycle with a maximum stress $\left(\sigma_{\max }\right)$ equal to $100 \%$ of the yield strength of the parent material and a loading stress ratio $(\mathrm{R}=0.1)$ is performed, Low Cycle Fatigue (LCF). The 
hardness variation all over the weld cross sectional area was measured using a fully automated Tukon microhardness tester machine with a motorized stage in a $0.7 \mathrm{~mm}$ step in both $\mathrm{X}$ and $\mathrm{Y}$ directions.

\section{Results and Discussion:}

The FSWd plates were examined optically in diferent zones along the plate width to evaluate the microstructure variation around the weld line. These zones are clearly illustrated in the macrostructure shown in Fig2(a) because of the effect of selective etching. In the shown figure, the thermo-mechanically affected zone in the advancing side of the weld is observed wider than that in the retreating side where this zone is a function of the welding parameter, as well as, the tool rotation direction as explained by Reynold et al [19]. Figure2(b) shows the microstructure of the parent material with well defined parallel bands of pearlite surrounded by the ductile coarse equiaxed ferritic grains. They exhibit a permanent texture and promote an initial anisotropy.
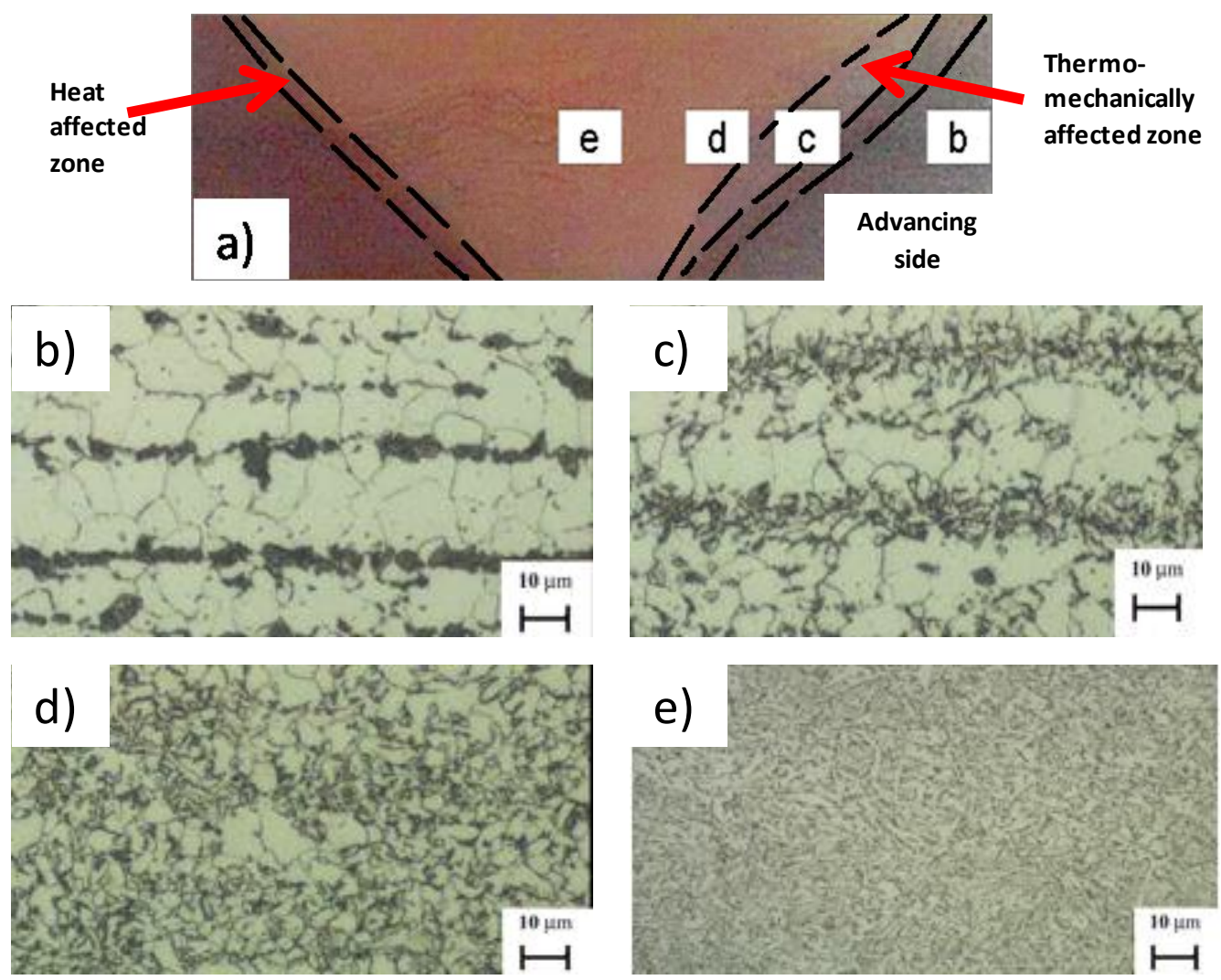

Fig. 2. Macro and microstructure variation around the weld line

Earlier investigation by Geffroy et al [23] reported the existence of some inclusions as carbon nitrides, niobium and zirconium carbides, as well as calcium sulphides, in negligible proportions which may have a substantial effect on the grain growth. Approaching the weld center, the banded microstructure presented in Fig2(b) is continually changing to more uniform, fine acicular structure. Proportionally with the deformation severity, exerted on the joint 
material, the newly recrystallized pearlite grains are more scattered and more effectively dispersed Fig2(c-e). To evaluate the weld performance and to compare its properties with the parent material, the FSWd joints with the different thicknesses are loaded quasi-statically in direction perpendicular to the weld line. Nearly, all these loaded specimens fractured and failed away from the weld region, in the parent material, as shown in Fig3a. Visual investigation of the fracture surface showed symptoms of ductile failure, where further investigation by the scanning electron microscope (SEM) revealed the existence of equiaxed dimples in the center Fig $3 \mathrm{~b}$ and gradually elongated grains in the rugged area towards the fractured specimen edges. Applying the predetermined fatigue regime on the FSWd joints promote their failure along the boundary of the tool shoulder marks and the parent material. Fatigue life in the range of 170 to 270 thousand cycles was recorded as a function of the joint thickness, whereas this range is almost tripled when the shoulder marks had been removed. All the fatigue loaded specimens were fractured in a plane parallel to the weld line, perpendicular to the top surface and went through the specimen thickness, through thickness fracture, Fig4.

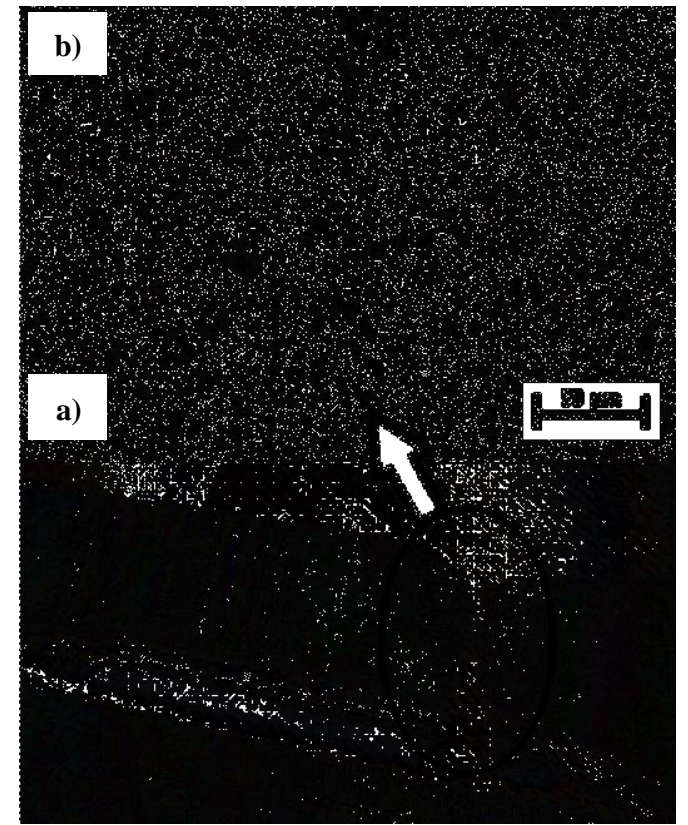

Fig. 3. Fracture of statically loaded joint a) fracture in the parent material b) fracture topography showing ductile failure mode.
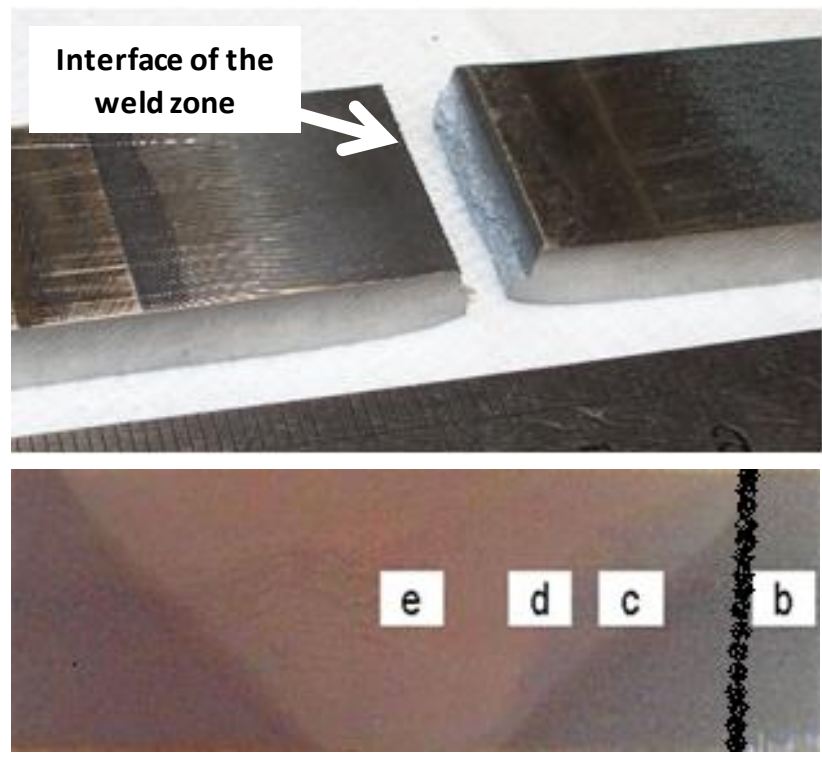

Fig. 4. Fracture of fatigue loaded joint in plane parallel to the weld line and perpendicular to the top surface

Compared with that fracture observed in Fig3, in the parent material, the fracture shows less reduction in the specimen cross section and indicates a brittle failure. Top surface of the fracture joint shows repeated hills and valleys representing the tool shoulder marks, Fig5. Related to the observed hills, there are parallel protuberances perpendicularly oriented to the top surface (fracture surface). Negative topography of these protuberances is stamped in the other side forming cavities. Micro observation of these cavities with suitable magnification showed 
the existence of surface micro-cracks that have been nucleated on the roots of the pre-existing stress concentrators, grooves of the tool shoulder marks, Fig6. Fatigue loading of the welded joints enhances the observed micro-cracks propagation and consequently the material fracture.

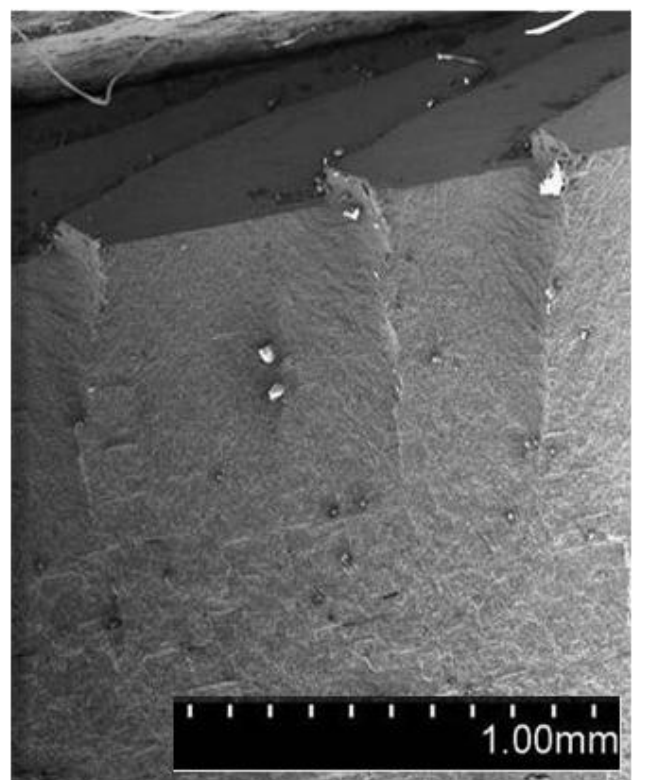

Fig. 5. Parallel protuberances related to the tool shoulder marks
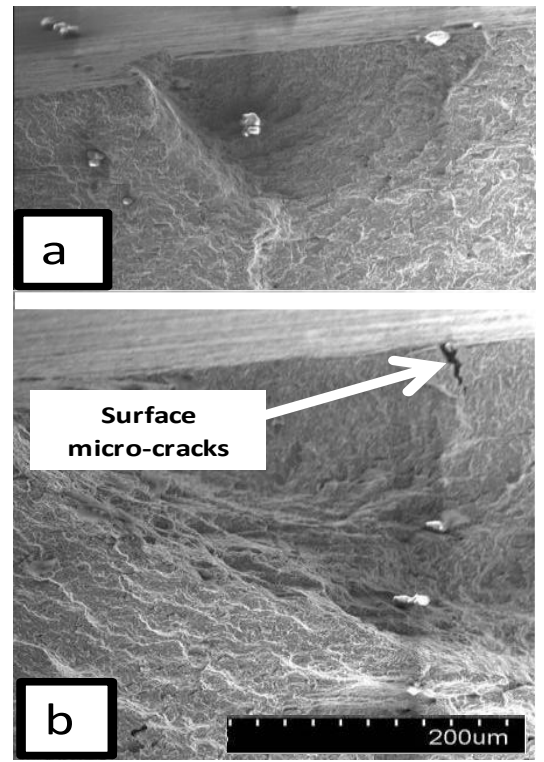

Fig. 6. Fracture surface at the weld interface a) cavity b) surface microcrack

As shown in Fig7, a hardness map is presented to illustrate the hardness variation through the friction stir joint. Plastic deformation exerted by the stirring tool hardened the stirred material with a decreasing gradient towards the parent material. In correspondence with Fig4, the fracture is nucleated in the interface of the tool shoulder marks with the parent material and propagated through the material showing minimum hardness. The tool shoulder marks are considered as sharp mechanical notches, which raise the stress level in their roots and encourages the surface micro-cracks opening for crack nucleation. Joint failure that takes place exactly in the tool shoulder marks interface could be attributed to the direction of the applied tensile stress relative to the transverse direction of these marks, as shown in Fig8.

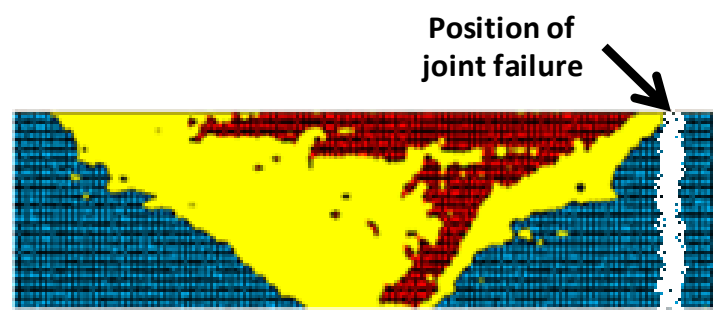

口240-300 180-240 ם120-180

Fig. 7. Hardness map of the weld and parent material

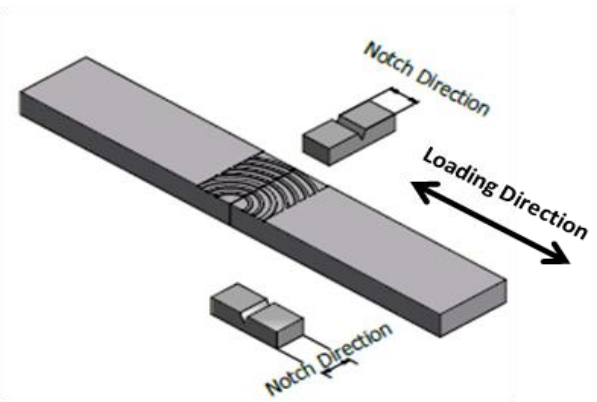

Fig. 8. Orientation of tool marks relative to the loading direction and the state of stress on the crack tip 
At the center of the weld, the loading axis is tangential to the tool mark grooves, which does not encourage the opening mode of the surface micro-cracks in the roots region. In the interface position, the applied stress is almost perpendicular to the tool mark grooves which enhances this opening and promotes their propagation. Different fracture profiles are observed as a function of the plate thickness, Fig9.

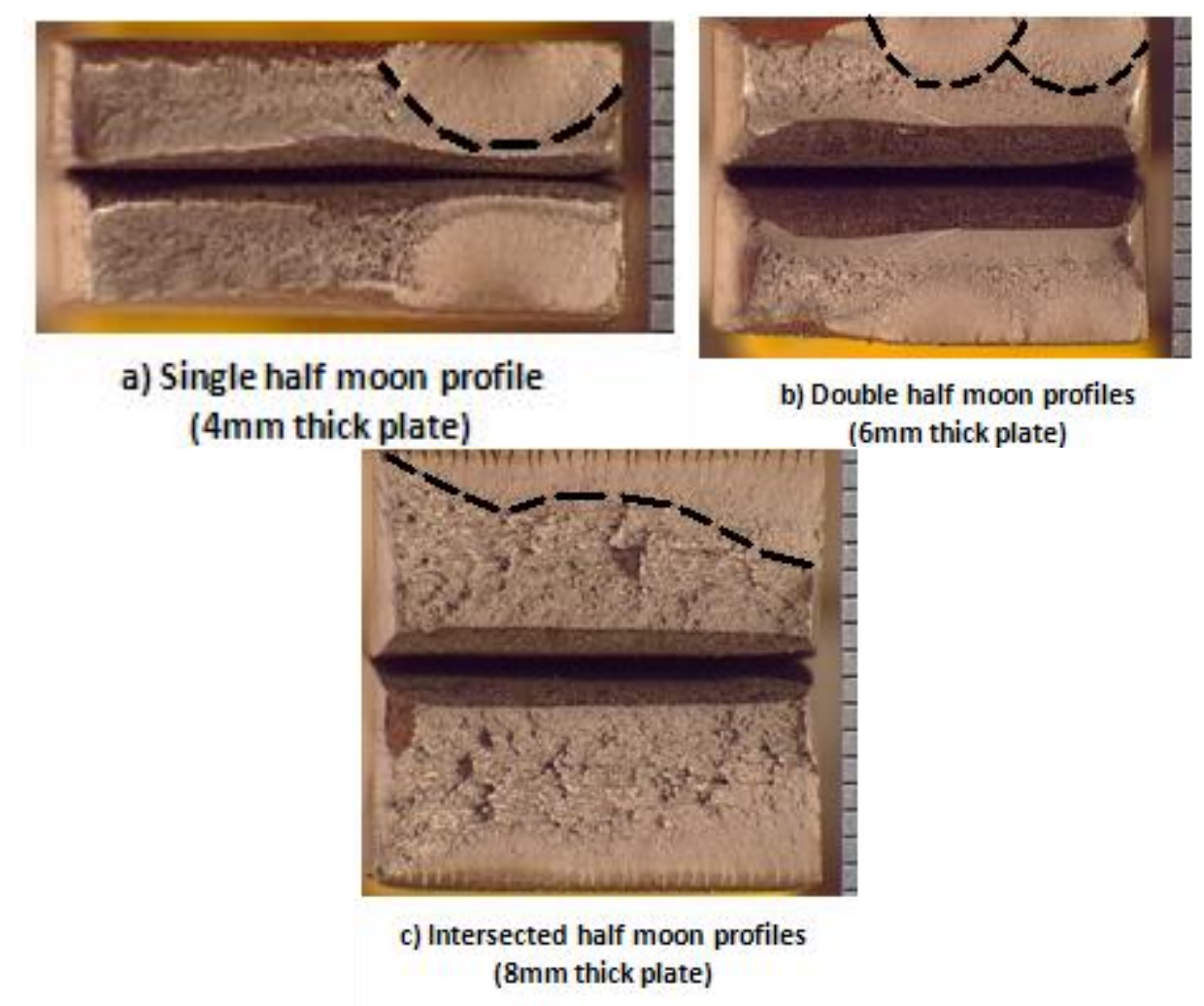

Fig. 9. Effect of plate thickness on the fracture profile of the fatigue loaded specimens

In all cases, a set of pre-created surface micro-cracks with different tip radii by the tool shoulder were subjected to an opening stress mode. Repeating the loading cycle(s), fatigue loading, expands the length of the surface micro-cracks where the stress intensity factor $(\mathrm{K})$ controls the speed of the crack propagation. In case of thick plates, namely $4 \mathrm{~mm}$, the fractured surface shows a single half moon failure pattern covering most of the plate thickness, Fig9a. Area of the half moon pattern shows the typical symptoms of fatigue crack nucleation and propagation. The reduced cross-sectional area of the joint was failed by over loading. Fracture surface of the thicker plate, $6 \mathrm{~mm}$, is shown in Fig9b where two halves of the same pattern are present. To explain this behavior, more focus should be paid to the effect of the material thickness (the only parameter have been changed) on the stress intensity factor in the tip of the micro-cracks. Glinka [24] reported that, the value of this factor is sensibly decreased by increasing the investigated material thickness. Thus, in the former case, the high stress intensity factor in the tips of the nucleated micro-cracks promotes their opening. Depending on the structural (crack length and tip radii) and/or the morphological conditions in the front of these cracks tip (phase present, grain 
morphology and second phase particles) there would be a single candidate micro-crack to propagate faster than the others. As a result, the candidate crack with the highest $\mathrm{K}$ factor propagates in radial direction(s) having a center in the plate surface to create the single half moon pattern. Once the candidate crack starts propagation, the stress level on the other crack tips is relaxed and their propagation is suppressed. Meanwhile, in the lateral case, the lower intensity factor $\mathrm{K}$ retards the micro-cracks propagation and allows more than one surface micro-crack to reach the critical length and start propagation simultaneously through the thickness. This allows the formation of intersected half moon patterns covering higher fraction of the loaded sectional area. In case of the thicker joint, $8 \mathrm{~mm}$ thick, the stress intensity is reduced to lower levels allowing propagation of most of the closely spaced surface micro-cracks in the roots of the mark grooves in multi half moon patterns. These patterns overlap together forming a planar propagation wave front rather than separate radial half moons as shown in Fig 9c.

Dependence of stress intensity factor $(\mathrm{K})$ upon the through thickness crack length (a), Fig 10, was calculated using the simple integration of the stress field $\sigma(x)$ product and the weight function $\mathrm{m}(\mathrm{x}, \mathrm{a})$ along the crack length [24], where $\mathrm{x}$ is the distance from the joint surface.

$k=\int_{0}^{a} \sigma(x) m(x, a)$

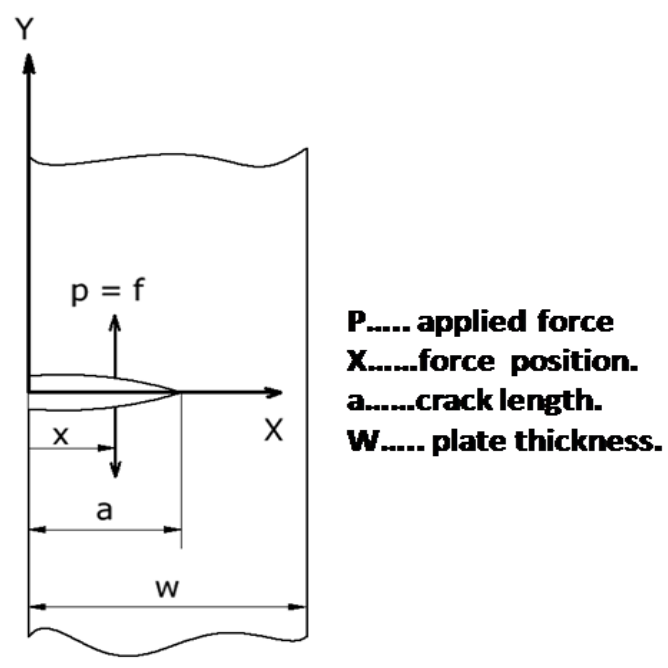

Fig. 10. Surface crack orientation relative to the plate thickness

Since all the investigated thicknesses almost have the same stirring parameter (stress concentrator root curvatures, applied stress cycles and applied stress frequency) the loading function $\sigma(x)$ could be assumed to be constant. Therefore, equation (1) could be written in the following form:

$k=\sigma(x) \int_{0}^{a} m(x, a)$

Moftakhar and Glinka [25] simplified considerably the calculation of stress intensity factors and formulated the equation constants. Therefore, the weight 
function will be rewritten in the following form taking into consideration that the $(\mathrm{w})$ value is related to the plate thickness as shown in Figure 10;

$\mathrm{m}(\mathrm{X}, \mathrm{a})=\frac{2}{\sqrt{2 \pi(a-x)}}\left[1+M_{1}\left(1-\frac{x}{a}\right)^{1 / 2}+M_{2}\left(1-\frac{x}{a}\right)^{1}+M_{3}\left(1-\frac{x}{a}\right)^{3 / 2}\right\rfloor$

Where,

$$
\begin{gathered}
M_{1}=0.0719768-1.51346\left(\frac{a}{w}\right)-61.1001\left(\frac{a}{w}\right)^{2}+1554.95\left(\frac{a}{w}\right)^{3}-14583.8\left(\frac{a}{w}\right)^{4}+ \\
71590.7\left(\frac{a}{w}\right)^{5}-205384\left(\frac{a}{w}\right)^{6}+356469\left(\frac{a}{w}\right)^{7}-368270\left(\frac{a}{w}\right)^{8}+208233\left(\frac{a}{w}\right)^{9}- \\
49544\left(\frac{a}{w}\right)^{10} \\
M_{2}=0.246984+6.47583\left(\frac{a}{w}\right)+176.456\left(\frac{a}{w}\right)^{2}-4058.70\left(\frac{a}{w}\right)^{3}+37303.8\left(\frac{a}{w}\right)^{4}- \\
181755\left(\frac{a}{w}\right)^{5}+520551\left(\frac{a}{w}\right)^{6}-904370\left(\frac{a}{w}\right)^{7}+936863\left(\frac{a}{w}\right)^{8}-531940\left(\frac{a}{w}\right)^{9}+ \\
M_{3}=0.529659-22.3235\left(\frac{a}{w}\right)+532.074\left(\frac{a}{w}\right)^{2}-5479.53\left(\frac{a}{w}\right)^{3}+28592.2\left(\frac{a}{w}\right)^{4}- \\
81388.6\left(\frac{a}{w}\right)^{5}+128746\left(\frac{a}{w}\right)^{6}-106246\left(\frac{a}{w}\right)^{7}+35780.7\left(\frac{a}{w}\right)^{8}
\end{gathered}
$$

Solving these equations for a fixed ratio $(x / a=0.5)$, crack length (a from 0 to $1 \mathrm{~mm})$ and discrete plate thicknesses $(4,6$ and $8 \mathrm{~mm})$ enables the calculation of the weight function and consequently the prediction of the stress intensity factor on the crack tip during its propagation. As shown in Figure 11, the weight function $\mathrm{m}(\mathrm{x}, \mathrm{a})$ on the short cracks tip showed similar values for all the investigated thicknesses till reaching a critical value of $0.1 \mathrm{~mm}$. Beyond this length, the weight function and consequently the stress intensity factor increase proportionally but with different rates. The steeper the slope of this dependence the higher the stress intensity factor with the lower plate thicknesses.

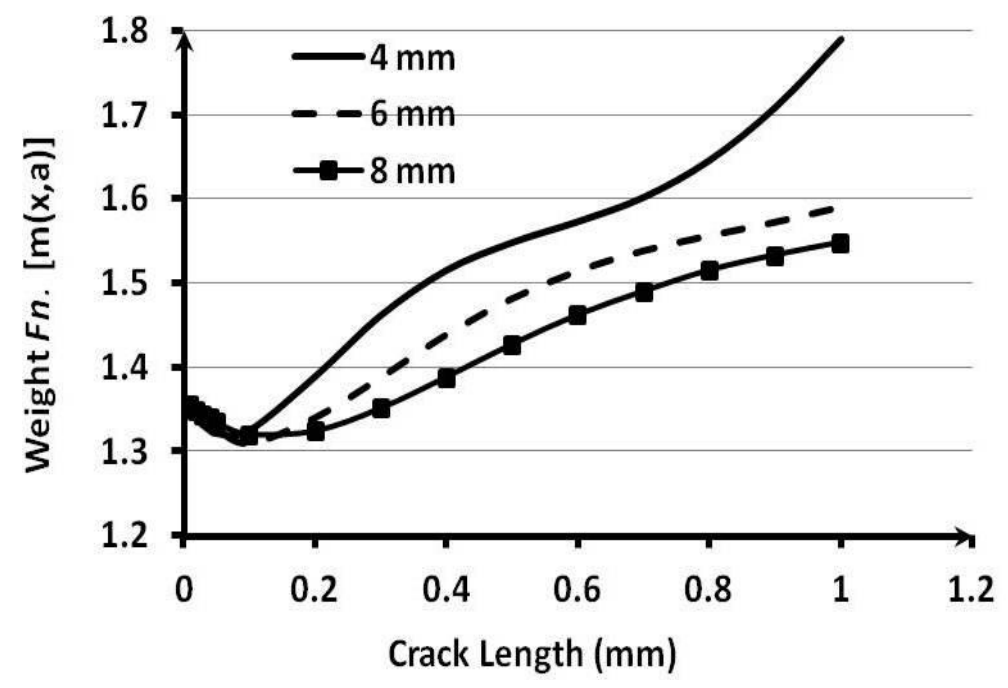

Fig. 11. Weight function versus the fatigue crack length for different plate thicknesses 


\section{Conclusions:}

1- The FSW process eliminates the microstructure non-homogeneity, therefore the joint is more isotropic.

2- The FSWd joint strength and hardness are substantially higher than those of the parent material.

3- Fatigue loading enhances surface micro-cracks propagation in the interface of the tool shoulder marks and the parent material.

4- Value of the stress intensity factor $(\mathrm{k})$ on the nucleated crack tip is almost the same for all thicknesses $(4,6$ and $8 \mathrm{~mm})$ till reaching a critical crack length of $0.1 \mathrm{~mm}$.

5- Beyond the critical crack length, the stress intensity factor is continuously increasing with different rates, inversely proportional to the plate thickness, which alters the observed fracture profiles.

6- In thin plates, $4 \mathrm{~mm}$ thickness, the high stress intensity factor on the nucleated crack tip enhances the crack propagation through the plate thickness in a single half moon profile but suppress the nucleation and propagation of the competing cracks.

7- In intermediate plate thickness, namely $6 \mathrm{~mm}$, the stress intensity factor is reduced on the crack tip that encourages simultaneous propagation of more than one crack.

8- In thicker plates, $8 \mathrm{~mm}$ thick, the stress intensity is reduced to lower levels allowing the closely spaced surface micro-cracks to propagate in the same time in multi half moon profiles. These patterns overlap together forming a planar propagation wave front rather than separate radial half moons.

\section{Acknowledgements}

The authors would like to acknowledge the valuable support of the technical team in the Advanced Materials Research Laboratory (AMRL) in Strathclyde University. The "BAE systems" is also acknowledged for supplying the material and for constructive guidance in all stages.

\section{Refrences:}

[1] W.M. Thomas, E.D. Nicholas, J.C. Needham, M.G. Murch, P. Templesmith and C.J. Dawes, Patent Application No.9125978.8 (December 1991).

[2] C. Dawes and W. Thomas, TWI Bulletin 6, (November 1995).

[3] R.S. Mishra and Z.Y. Ma, Materials Science and Engineering R 50 (2005) 1. [4]G. Liu, L.E. Murr, C.S. Niou, J.C. McClure and F.R. Vega, Scripta Materillia 37 (1997) 355.

[5] S. Benavides, Y. Li, L.E. Murr, D. Brown and J.C. McClure, Scripta Materillia 41 (1999) 809.

[6] Y.S. Sato, H. Kokawa, M. Enmoto, S. Jogan and T. Hashimoto, Metallurgical Materials Transactions A 30 (1999) 3125. 
[7] Y.S. Sato, H. Kokawa, M. Enmoto, S. Jogan and T. Hashimoto, Metallurgical Materials Transactions A 32 (2001) 941.

[8] Y.S. Sato, S.H.C. Park and H. Kokawa, Metallurgical Materials Transactions A 32 (2001) 3023.

[9] L.E. Svesson, L. Karlsson, H. Larsson, B. Karlsson, M. Fazzini and J. Karlsson, Science Technology Welding and Joining 5 (2000) 285.

[10] W.M. Thomas, P.L. Threadgill and E.D. Nicholas, Science Technology Welding and Joining 4 (1999) 365.

[11] T.J. Lienert and J.E. Gould, in: The $1^{\text {st }}$ International Symposium on Friction Stir Welding (Thousand Oaks, CA, USA, 1999).

[12] T.J. Lienert, W.L. Stellwag, B.B. Grimmett and R.M. Warke, Welding Journal 82(1) (2003) 1.

[13] A. Reynolds, M. Posada, J. Deloach, M.J. Skinner, J. Halpin and T.J. Lienert, In: The $3^{\text {rd }}$ International Symposium on Friction Stir Welding, (Kobe, Japan, 2001)......

[14] M. Posada, J. Deloach, A.P. Reynolds, M. Skinner, J.P. Halpin, in: K.V. Jata, M.W. Mahoney, R.S. Mishra, S.L. Semiatin, D.P. Filed (Eds.), Friction Stir Welding and Processing (TMS, Warrendale, PA, USA, 2001) p. 159.

[15] S.H.C. Park, Y.S. Sato, H. Kokawa, K. Okamoto, S. Hirano and M. Inagaki, Scripta Materillia 49 (2003) 1175.

[16] R. Johnson and P.L. Threadgill, In: S.A. David, T. DebRoy, J.C. Lippold, H.B. Smartt, J.M. Vitek (Eds.), The $6^{\text {th }}$ International Conference on Trends in Welding Research (Pine Mountain, GA, ASM International, 2003) p.88.

[17] P.J. Konkol, J.A.Mathers, R. Johnson, J.R. Pickens, In: The $3^{\text {rd }}$ International Symposium on Friction Stir Welding, (Kobe, Japan, 2001)....

[18] M. Posada, J. Deloach, A.P. Reynolds, J.P. Halpin, In: S.A. David, T. DebRoy, J.C. Lippold, H.B. Smartt, J.M. Vitek (Eds.), The $6^{\text {th }}$ International Conference on Trends in Welding Research (Pine Mountain, GA, ASM International, 2003) p.307.

[19] A.P. Reynolds, W. Tang, M. Posada and J. Deloach, Science Technology Welding and Joining 8(6) (2003) 455.

[20] C.J. Sterling, T.W. Nelson, C.D. Sorensen, R.J. Steel, S.M. Packer, In: K.V. Jata, M.W. Mahoney, R.S. Mishra, S.L. Semiatin, T. Lienert (Eds.), Friction Stir Welding and Processing II, TMS, 2003, p. 165.

[21] G. Bussu and P.E. Irving, In: The $1^{\text {st }}$ International Symposium on Friction Stir Welding (Thousand Oaks, CA, USA, 1999).

[22] L. Magnusson and L. Kallman, In: The $2^{\text {nd }}$ International Symposium on Friction Stir Welding (Gothenburg, Sweden, 2000) 26.

[23] A. Geffroy, P. Longère and B. Leblé, Engineering Failure Analysis 18 (2011) 670.

[24] G. Glinka, Stress and Fatigue-Fracture Design, Progress Report, (Ontario, Canada 1996).

[25] A. Moftakhar, G. Glinka, Engineering Fracture Mechanics 43(5) (1992)749. 